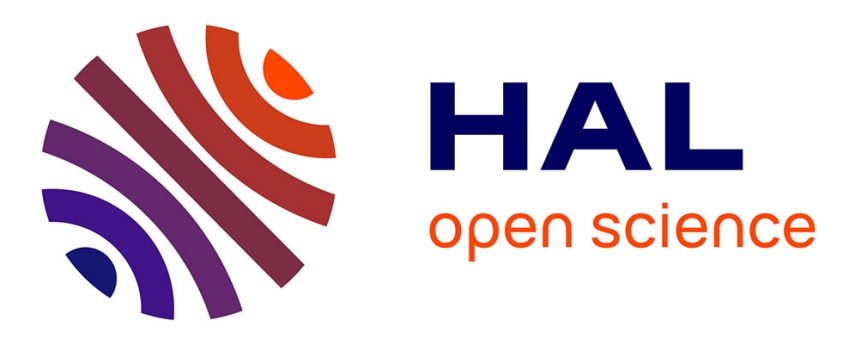

\title{
NADPH oxidase-derived superoxide impairs calcium transients and contraction in aged murine ventricular myocytes
}

\author{
Uwe Rueckschloss, Marten Villmow, Udo Klöckner
}

\section{- To cite this version:}

Uwe Rueckschloss, Marten Villmow, Udo Klöckner. NADPH oxidase-derived superoxide impairs calcium transients and contraction in aged murine ventricular myocytes. Experimental Gerontology, 2010, 45 (10), pp.788. 10.1016/j.exger.2010.05.002 . hal-00625937

\section{HAL Id: hal-00625937 \\ https://hal.science/hal-00625937}

Submitted on 23 Sep 2011

HAL is a multi-disciplinary open access archive for the deposit and dissemination of scientific research documents, whether they are published or not. The documents may come from teaching and research institutions in France or abroad, or from public or private research centers.
L'archive ouverte pluridisciplinaire HAL, est destinée au dépôt et à la diffusion de documents scientifiques de niveau recherche, publiés ou non, émanant des établissements d'enseignement et de recherche français ou étrangers, des laboratoires publics ou privés. 


\section{Accepted Manuscript}

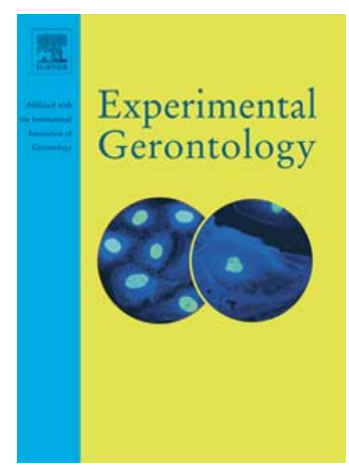

NADPH oxidase-derived superoxide impairs calcium transients and contraction in aged murine ventricular myocytes

\section{Uwe Rueckschloss, Marten Villmow, Udo Klöckner \\ PII: $\quad$ S0531-5565(10)00191-9 \\ DOI: $\quad$ doi: $10.1016 /$ j.exger.2010.05.002 \\ Reference: $\quad$ EXG 8748}

To appear in: $\quad$ Experimental Gerontology

Received date: 13 January 2010

Revised date: $\quad 6$ May 2010

Accepted date: 12 May 2010

Please cite this article as: Rueckschloss, Uwe, Villmow, Marten, Klöckner, Udo, NADPH oxidase-derived superoxide impairs calcium transients and contraction in aged murine ventricular myocytes, Experimental Gerontology (2010), doi: 10.1016/j.exger.2010.05.002

This is a PDF file of an unedited manuscript that has been accepted for publication. As a service to our customers we are providing this early version of the manuscript. The manuscript will undergo copyediting, typesetting, and review of the resulting proof before it is published in its final form. Please note that during the production process errors may be discovered which could affect the content, and all legal disclaimers that apply to the journal pertain. 
NADPH oxidase-derived superoxide impairs calcium transients and contraction in aged murine ventricular myocytes

Uwe Rueckschloss*, Marten Villmow, Udo Klöckner

Julius Bernstein Institute of Physiology, Martin Luther University Halle

Corresponding author:

Uwe Rueckschloss

Martin Luther University Halle

Julius Bernstein Institute of Physiology

Magdeburger Strasse 6

D-06097 Halle

Germany

phone: $+49-345-5574434$

fax: +49-345-557 4019

e-mail: uwe.rueckschloss@medizin.uni-halle.de

\section{Abstract}

Since aging increases oxidative stress, we analyzed the contribution of reactive oxygen species (ROS) to the contractile dysfunction of aged ventricular myocytes and investigated whether short-term interference with ROS formation could normalize contractile performance.

Isolated ventricular myocytes from young (2-4 months) and aged (24-26 months) male mice (C57BL/6) were used. We analyzed sarcomere shortening and calcium transients 
(Indo-1 fluorescence) of voltage clamped ventricular myocytes and myofilament ATPase activity (malachite green assay). Expression of calcium handling proteins (Western blots) and NADPH oxidase subunits (real-time PCR) was quantified, as well as NADPH oxidase activity (lucigenin chemiluminescence).

We found that aged myocytes showed decelerated shortening/ relengthening without changes in fractional shortening. Calcium transient decay was similarly decelerated, but the amplitude of calcium transients was increased with aging. Calcium sensitivity of myofilaments of aged myocytes was reduced. These age-dependent changes occurred without altered calcium handling protein expression but were reversed by the superoxide scavenger tiron.

Aged myocytes showed increased NADPH oxidase expression and activity. Pharmacological inhibition of NADPH oxidase (diphenylene iodonium; apocynin) normalized age-dependent deceleration of shortening/ relengthening.

In summary, we show that increased superoxide formation by upregulated NADPH oxidase contributes significantly to age-dependent alterations in calcium handling and contractility of murine ventricular myocytes.

Key words: aging; cardiac myocytes; calcium transient; myofilament ATPase; contraction; reactive oxygen species; oxidative stress; NADPH oxidase

\section{Introduction}

The aging heart is characterized by changes in the calcium handling of cardiac myocytes. Particularly the calcium removal from the cytosol by re-uptake into the sarcoplasmic reticulum (SR) is decelerated in aged cardiac myocytes favouring the development of diastolic dysfunction at higher frequencies (Lakatta, 1993). Slowed 
relengthening of isolated aged ventricular myocytes was also demonstrated in rodent models of cardiac aging (Capasso et al., 1992; Li et al., 2005; Yang et al., 2006).

In the human heart age-dependent diastolic dysfunction was attributed to a reduced expression of the SR calcium ATPase SERCA2 (Lakatta, 1993). Similarly, in aged rat hearts reduced SERCA2 expression and activity was demonstrated (Buttrick et al., 1991; Froehlich et al., 1978; Lompre et al., 1991). Li et al. (2007) recently reported reduced SERCA2 expression and activity in aged hearts of FVB mice, whereas we previously showed diastolic dysfunction in aged ventricular myocytes of C57BL/6 mice without changes in protein expression of SERCA2 (Isenberg et al., 2003). Therefore, depending on the strain used calcium handling may be additionally modulated by posttranslational mechanisms in aged rodent ventricular myocytes.

It was suggested that reactive oxygen species (ROS) are involved in age-related dysfunction. Concerning the aged rat heart, increased ROS formation by mitochondrial electron transport chain or NADPH oxidase and reduced activity of the antioxidative enzyme superoxide dismutase were reported that promote a prooxidative shift in redoxbalance (Adler et al., 2003; Sawada and Carlson, 1987; van der Loo et al., 2005). Calcium handling of cardiac myocytes is redox-sensitive. Perfusion of isolated rabbit hearts with hydrogen peroxide increased cytosolic calcium concentration (Corretti et al., 1991) and TNF- $\alpha$ or ischemia induce changes in calcium handling that are normalized by application of ROS scavengers (Cailleret et al., 2004; Dworschak et al., 2004). Recently, it was reported that lifelong constitutive overexpression of antioxidative enzymes prevents age-dependent diastolic dysfunction in murine ventricular myocytes providing further evidence for oxidative stress to be involved (Dai et al., 2009; Ren et al., 2007; Yang et al., 2006). 
Nevertheless, the role of ROS for contractile dysfunction of cardiac myocytes and its sources have not been directly proven in aged non-transgenic mice. Furthermore, it remains to be elucidated whether contractile dysfunction can not only be prevented by lifelong interventions but once established also can be reversed i.e. by antioxidative treatment.

To address these questions, we determined expression of calcium handling proteins and NADPH oxidase subunits. We analyzed contraction, calcium transients and myofilament ATPase activity of isolated ventricular myocytes from young and aged mice. To identify the role of ROS and NADPH oxidase, pharmacological approaches were used.

We show that increased superoxide formation by upregulated NADPH oxidase significantly contributes to age-dependent alterations in calcium transients and myofilament function that result in contractile dysfunction of aged murine ventricular myocytes.

\section{Material \& Methods}

Isolation of murine ventricular myocytes

All procedures were approved by the local authorities and conform to the Guide for the Care and Use of Laboratory Animals published by the US National Institutes of Health (NIH Publication No. 85-23, revised 1996). We used young (2-4 months) and aged (2426 months) male mice of the C57BL/6 strain. Mice were killed by cervical dislocation and ventricular myocytes were isolated by standard collagenase dissociation technique as previously described (Kamkin et al., 2003).

\section{Contraction}


Myocytes were superfused with tyrode solution $\left(1.8 \mathrm{mmol} / \mathrm{L}\right.$ calcium, $\left.37^{\circ} \mathrm{C}\right)$ and voltage clamped to a holding potential of $-80 \mathrm{mV}$. Electrode solution was composed of (in mmol/L) $140 \mathrm{CsCl}, 5 \mathrm{NaCl}, 4 \mathrm{Na}_{2} \mathrm{ATP}, 4.5 \mathrm{MgCl}_{2}$, 0.005 EGTA and 10 Hepes (pH 7.4). Trains of voltage steps were continuously applied at $0.5 \mathrm{~Hz}$ (10 ms pre-pulse to -45 $\mathrm{mV}$ followed by test-pulse to $0 \mathrm{mV}$ for either $40 \mathrm{~ms}$ (short pulse) or $160 \mathrm{~ms}$ (long pulse)). After equilibration (3 min) frequency was sequentially increased: $0.5,1,2,4$ and $6 \mathrm{~Hz}$ (1 min each; $6 \mathrm{~Hz}$ for short pulses only).

Sarcomere length was continuously recorded using the IonOptix MyoCam system (scan rate $240 \mathrm{~Hz}$ ). The last 10 contractions of every frequency train were averaged for fractional sarcomere shortening, time to peak shortening (TPS) and time to $70 \%$ relengthening $\left(\mathrm{TR}_{70}\right)$ using IonOptix software.

Pre-incubations with tiron $(1 \mathrm{mmol} / \mathrm{L}$; Fluka), diphenylene iodonium (DPI, $10 \mu \mathrm{mol} / \mathrm{L}$; Sigma) or apocynin $(50 \mu \mathrm{mol} / \mathrm{L}$; Sigma) were done for at least 2-3 hours.

\section{Calcium transients}

Myocytes were loaded with Indo-1 AM (5 $\mu \mathrm{mol} / \mathrm{L}$; Invitrogen) for 30 minutes. Myocytes were superfused with tyrode solution $\left(1.8 \mathrm{mmol} / \mathrm{L}\right.$ calcium, $\left.37^{\circ} \mathrm{C}\right)$ and voltage clamped to a holding potential of $-80 \mathrm{mV}$. Electrode solution was composed of (in mmol/L) $140 \mathrm{KCl}, 5 \mathrm{Na}_{2} \mathrm{ATP}, 6 \mathrm{MgCl}_{2}, 0.005$ EGTA, 10 Hepes (pH 7.4). Myocytes were continuously stimulated with voltage steps at $1 \mathrm{~Hz}(10 \mathrm{~ms}$ pre-pulse to $-45 \mathrm{mV}$ followed by $160 \mathrm{~ms}$ test-pulse to $0 \mathrm{mV}$ ). The cells were excited at $340 \mathrm{~nm}$. Emission was collected and amplified in bands of $395-425 \mathrm{~nm}$ and $450-490 \mathrm{~nm}$. Background fluorescence at $410 \mathrm{~nm}$ and $470 \mathrm{~nm}$ was digitally subtracted before fluorescence ratio $410 \mathrm{~nm} / 470 \mathrm{~nm}$ of Indo-1 loaded cells was calculated. For analysis, 10 consecutive 
traces of stimulation were averaged offline for transient amplitude, time to peak systolic calcium concentration (TPC) and time to $70 \%$ calcium decay $\left(\mathrm{TD}_{70}\right)$.

\section{Myofilament ATPase activity}

Myofilaments were prepared as described by Pi et al. (2003). Isolated cardiac myocytes were homogenized in relaxing buffer composed of (in mmol/L) $100 \mathrm{KCl}, 1 \mathrm{MgCl}_{2}$, 2 EDTA, 1 DTT, 20 Pipes (pH 7.0), BSA (1 g/L), protease inhibitor cocktail (1:100; Sigma) and Ser/Thr phosphatase inhibitor cocktail (1:200; Sigma). It was supplemented with $5 \mathrm{mmol} / \mathrm{L} \mathrm{Na} \mathrm{NTP}_{2}$ and $0.33 \%$ Triton $\mathrm{X}-100$. The homogenate was left on ice for 20 min. The myofilaments were pelleted, washed twice with and resuspended in relaxing buffer (without supplements).

Myofilament ATPase activity was determined according to Swartz et al. (1999) with modifications. The activation buffer was composed of (in mmol/L) $130 \mathrm{KCl}, 4 \mathrm{MgCl}_{2}, 1$ $\mathrm{NaN}_{3}, 1$ DTT, $4 \mathrm{Na}_{2}$ ATP, 2 EDTA, 2 EGTA, 2 HEDTA, 20 Pipes (pH 7.0) BSA (1 g/L), protease inhibitor cocktail (1:100; Sigma) and Ser/Thr phosphatase inhibitor cocktail (1:200; Sigma). The ATPase reaction was carried out at $30^{\circ} \mathrm{C}$ using $10 \mu \mathrm{g}$ of myofilaments in a total volume of $100 \mu \mathrm{L}$ activation buffer supplemented with $\mathrm{CaCl}_{2}$ to yield different free $\mathrm{Ca}^{2+}$ concentrations (pCa 6.5 to 4.0; calculated using the WEBMAX C program at http://www.stanford.edu/ cpatton/webmaxc). After $10 \mathrm{~min}$ the reaction was stopped by addition of $50 \mu \mathrm{L}$ ice-cold $25 \%$ TCA. Within this time, the reaction was linear using the highest calcium concentration ( $\mathrm{pCa} 4.0)$.

The generated inorganic phosphate $\left(\mathrm{P}_{\mathrm{i}}\right)$ was quantified by the malachite green assay (Carter and Karl, 1982). $20 \mu \mathrm{L}$ of the supernatants from TCA precipitations were diluted to $100 \mu \mathrm{L}$. Subsequently, $70 \mu \mathrm{L}$ of solution A (42 mmol/ $\mathrm{L} \mathrm{Na}_{2} \mathrm{MoO}_{4}$ dissolved 
in $1 \mathrm{~mol} / \mathrm{L} \mathrm{HCl}), 30 \mu \mathrm{L}$ of solution $\mathrm{B}(0.042 \%$ malachite green in $1 \%$ polyvinyl alcohol $)$ and $30 \mu \mathrm{L}$ of solution $\mathrm{C}\left(30 \% \mathrm{H}_{2} \mathrm{SO}_{4}\right)$ were added. After colour development for at least $60 \mathrm{~min}$, absorption was read at $630 \mathrm{~nm}$.

Blebbistatin is a specific inhibitor of myosin II ATPase activity (Limouze et al., 2004). For every sample, ATPase reactions were performed using untreated myofilaments and blebbistatin pre-incubated myofilaments $(100 \mu \mathrm{mol} / \mathrm{L}, 20 \mathrm{~min})$. The difference was ascribed to phosphate generation by myofilament ATPase. Activity was determined as nmol $\mathrm{P}_{\mathrm{i}}(\mathrm{mg} \text { protein })^{-1} \min ^{-1}$ by comparison with a phosphate standard curve, which was linear to at least $500 \mu \mathrm{mol} / \mathrm{L} \mathrm{P}_{\mathrm{i}}$.

\section{Western blots}

Western blot analyses were performed using hearts that were perfused with normal tyrode solution $(1 \mathrm{~min})$. Thereafter, hearts were immediately shock-frozen in liquid nitrogen. Hearts were homogenized in lysis buffer composed of (in mmol/L) 20 Tris, 250 sucrose, 3 EGTA, 20 EDTA, plus $0.5 \%$ Triton X-100, 0.5\% SDS (pH 8.0), protease inhibitor cocktail (1:50; Sigma) and Ser/Thr phosphatase inhibitor cocktail (1:100; Sigma). After SDS-PAGE of total proteins and transfer onto polyvinylidene difluoride (PVDF) membranes, blots were incubated with antibodies specific for total phospholamban (Santa Cruz), DHP receptor $\alpha$ subunit (Dianova), RyR2 (Sigma) and Calsequestrin (Upstate). Blots were visualised using the ECL Western blotting analysis system (Amersham Pharmacia Biotech). To correct for putative differences in gel loading and protein transfer efficiency, immunological signals were normalised to a subsequent Ponceau S staining of the blot. Values are given in arbitrary units (a.u.). 


\section{NADPH oxidase activity}

NADPH oxidase activity was quantified by the lucigenin chemiluminescence assay using Krebs-Henseleit buffer composed of (in mmol/L): $146 \mathrm{NaCl}, 5 \mathrm{KCl}, 1 \mathrm{CaCl}_{2}, 0.35$ $\mathrm{NaH}_{2} \mathrm{PO}_{4}, 1 \mathrm{MgSO}_{4}, 10$ glucose and 10 Hepes (pH 7.4). Isolated myocytes were homogenized in Krebs-Henseleit buffer supplemented with protease inhibitor cocktail (1:100; Sigma). Homogenate (100 $\mu$ g), NADPH (100 $\mu \mathrm{mol} / \mathrm{L} ;$ Sigma) and dark adapted lucigenin ( $N, N^{\prime}$-dimethyl-9,9'-biacridinium dinitrate; $5 \mu \mathrm{mol} / \mathrm{L}$; Sigma) were combined to $1 \mathrm{ml}$ with Krebs-Henseleit buffer. Subsequently to additional 6 min of incubation in the dark, chemiluminescence was recorded for 1 min using the tube luminometer LB9507 (Berthold Technologies). In some experiments, tiron (10 mmol/L), diphenylene iodonium (DPI, $10 \mu \mathrm{mol} / \mathrm{L}$ ), or N-nitro-L-arginine methyl ester (L-NAME, 100 $\mu \mathrm{mol} / \mathrm{L}$ ) were included in the assay. Values are given as relative light units RLU (mg protein $)^{-1} \min ^{-1}$.

\section{Real-time PCR}

Total RNA of isolated ventricular myocytes was isolated according to the Tri ${ }^{\circledR}$ Reagent (Sigma) protocol. RNA concentration was determined by UV absorption at $260 \mathrm{~nm}$. Putative traces of contaminating DNA were eliminated by sample treatment with DNase I (Sigma) according to the manufacturer's protocol. Sample RNA was reverse transcribed at $42^{\circ} \mathrm{C}$ for $60 \mathrm{~min}$ using StrataScript ${ }^{\circledR}$ QPCR cDNA Synthesis Kit (Stratagene). A control reaction for each sample was processed identically but without enzyme.

Real-time PCR was performed in an Mx3005P (Stratagene) using FullVelocity ${ }^{\mathrm{TM}}$ SYBR $\circledast$ Green QPCR Master Mix (Stratagene). ROX fluorescence was used to 
normalize for volume differences between individual reactions. Mouse specific primer pairs for $C y b b$ (NOX2), NOX4, Cyba (p22phox), Ncf1 (p47phox), rac1, Slc8al (NCX1) and 18S rRNA were purchased from SuperArray Biosciences. All samples and controls were processed in triplicate with the following thermal cycling program: initial denaturation $\left(95^{\circ} \mathrm{C} ; 10 \mathrm{~min}\right)$ and 40 cycles of amplification (denaturation: $95^{\circ} \mathrm{C}, 1 \mathrm{~min}$; annealing: $57^{\circ} \mathrm{C}, 20 \mathrm{~s}$; synthesis: $72^{\circ} \mathrm{C}, 30 \mathrm{~s}$ ). At the end of each run, melting curve analysis validated PCR reactions (see online Supplementary material). One sample was denominated as "calibrator" and the amount of target in each sample was determined relative to the "calibrator". Amplification of $18 \mathrm{~S}$ rRNA was used as an internal control; mRNA values are given as ratios normalized to $18 \mathrm{~S}$ rRNA in arbitrary units (a.u.).

\section{Statistics}

All data are presented as mean \pm standard error for $\mathrm{n}$ experiments. Differences between groups were tested using t-tests or one way ANOVA where appropriate and considered significant when $\mathrm{P}<0.05$.

\section{Results}

\section{Contractions}

When paced with $40 \mathrm{~ms}$ voltage clamp pulses, fractional shortening of aged ventricular myocytes was smaller than in young myocytes. This difference became statistically significant with higher stimulation frequency $(2-6 \mathrm{~Hz})$. Pre-incubation with the superoxide scavenger tiron did not significantly improve fractional shortening in aged myocytes (table 1, Supplementary material). There were no significant differences in time to peak shortening (TPS) and time to $70 \%$ relengthening $\left(\mathrm{TR}_{70}\right)$ between young and aged myocytes paced with short pulses (data not shown). 
Representative recordings of a young and an aged cardiac myocyte paced with $160 \mathrm{~ms}$ voltage clamp pulses are shown in Fig. 1. This protocol induced calcium stress as indicated by after-contractions seen in young and aged myocytes, respectively. With increasing frequency, fractional shortening was reduced in both groups. However, young and aged myocytes shortened to the same extend. This was accompanied by a significant increase in TPS and $\mathrm{TR}_{70}$ in aged myocytes.

We analyzed, whether oxidative stress contributes to the prolonged TPS and $\mathrm{TR}_{70}$ of aged myocytes. Therefore, we pre-incubated aged myocytes with the superoxide scavenger tiron, with the flavoprotein inhibitor DPI or the NADPH oxidase inhibitor apocynin. These compounds had no effect on fractional shortening, but accelerated contraction kinetics and significantly reduced TPS and $\mathrm{TR}_{70}$ in aged myocytes (Fig. 2).

None of these interventions significantly affected fractional shortening, TPS or $\mathrm{TR}_{70}$ in young myocytes (data not shown).

\section{Calcium transients}

Representative calcium transients of a young myocyte, an aged myocyte and an aged myocyte pre-incubated with tiron are shown in Fig. 3. Statistical analyses indicated no difference in the time to peak calcium concentration (TPC) between the groups. However, the amplitude of the calcium transients was significantly increased in the aged myocytes (Young: $231 \pm 18$ a.u.; n=24; Aged: $306 \pm 26$ a.u.; n=32) and the time to $70 \%$ calcium decay $\left(\mathrm{TD}_{70}\right.$ ) was significantly prolonged (Young: $197 \pm 6 \mathrm{~ms} ; \mathrm{n=24}$; Aged: 237 $\pm 7 \mathrm{~ms} ; \mathrm{n}=32$ ). Pre-incubation of aged myocytes with tiron reversed age-dependent changes in transient amplitude (Aged + Tiron: $220 \pm 20$ a.u.; $\mathrm{n}=33$ ) and $\mathrm{TD}_{70}($ Aged + Tiron: $204 \pm 6 \mathrm{~ms} ; \mathrm{n}=33$ ). Pre-incubation with tiron of young myocytes had no effect on calcium transient parameters. 


\section{Myofilament ATPase activity}

Maximum myofilament ATPase activity at pCa 4.0 (Fig. 4A) did not differ between the young group $\left(264 \pm 13 \mathrm{nmol} \mathrm{P}_{\mathrm{i}}(\mathrm{mg} \text { protein })^{-1} \min ^{-1} ; \mathrm{n}=3\right)$ and the aged group $(273 \pm 19$ nmol $\left.\mathrm{P}_{\mathrm{i}}(\mathrm{mg} \text { protein })^{-1} \min ^{-1} ; \mathrm{n}=3\right)$. In both groups, pre-incubation of isolated myocytes with tiron had no effect on maximum myofilament ATPase activity.

However, compared to young myocytes the calcium response curve of myofilament ATPase activity of aged myocytes was shifted rightwards (Fig. 4B). Consequently, myofilament ATPase activity was significantly reduced in aged myocytes at $\mathrm{pCa} 6.0$ (Young: $190 \pm 5 \mathrm{nmol} \mathrm{P}_{\mathrm{i}}(\mathrm{mg} \text { protein })^{-1} \min ^{-1}$; $\mathrm{n}=3$; Aged: $142 \pm 8 \mathrm{nmol} \mathrm{P}_{\mathrm{i}}(\mathrm{mg} \text { protein })^{-1}$ $\min ^{-1} ; \mathrm{n}=3$ ). The reduced calcium sensitivity of ATPase activity from aged myofilaments was normalized by pre-incubation of aged myocytes with tiron. Hence, activity of myofilament ATPase at pCa 6.0 significantly increased (Aged + Tiron: 185 $\pm 11 \mathrm{nmol} \mathrm{P}_{\mathrm{i}}$ (mg protein $)^{-1} \min ^{-1} ; \mathrm{n}=3$ ). These values correspond to $72 \%$ (Young), $52 \%$ (Aged) and 74\% (Aged + Tiron) of the maximum myofilament ATPase activity.

Accordingly, there was a significant difference in the calcium concentration for halfmaximal myofilament ATPase activation between young and aged myocytes (Young: $0.72 \pm 0.08 \mu \mathrm{mol} / \mathrm{L}, \mathrm{n}=3$; Aged: $1.00 \pm 0.04 \mu \mathrm{mol} / \mathrm{L}, \mathrm{n}=3$; Fig. $4 \mathrm{~B}$ inset) that was normalized by pre-incubation with tiron (Aged + Tiron: $0.70 \pm 0.04 \mu \mathrm{mol} / \mathrm{L}, \mathrm{n}=3$ ). Tiron had no effect on calcium sensitivity of myofilament ATPase of young myocytes.

\section{Calcium handling protein expression}

We determined expression of proteins involved in the calcium cycling of cardiac myocytes (Fig. 5). The $\alpha$ subunit of the DHP receptor that is responsible for calcium 
influx was similarly expressed in young and aged murine hearts (Young: $3.0 \pm 0.1$ a.u., $\mathrm{n}=4$; Aged: $2.6 \pm 0.2$ a.u.; $n=5$ ). There were no differences in the protein expression of the SR calcium release channel RyR2 (Young: $1.7 \pm 0.4$ a.u., $n=4$; Aged: $1.7 \pm 0.2$ a.u.; $\mathrm{n}=5$ ) and calsequestrin, the intra-luminal SR calcium buffering protein (Young: $2.7 \pm 0.5$ a.u., $n=4$; Aged: $2.6 \pm 0.6$ a.u.; n=5). Phospholamban, a SERCA2-regulating protein also showed no difference between young and aged hearts (Young: $1.1 \pm 0.2$ a.u., $n=4$; Aged: $1.2 \pm 0.1$ a.u.; $n=5)$.

The expression of the sodium-calcium exchanger (NCX) was analyzed on mRNA level using real-time PCR. Normalized to the expression of $18 \mathrm{~S}$ rRNA, there was no difference in the expression of NCX between hearts from young and aged mice, respectively (Young: $0.91 \pm 0.13$ a.u., $\mathrm{n}=6$; Aged: $0.93 \pm 0.08$ a.u.; $\mathrm{n}=6$; no figure).

NADPH oxidase subunit expression and activity

Using total RNA prepared from isolated cardiac myocytes, we analyzed subunit mRNA expression of NADPH oxidases (Fig. 6A). Compared to young myocytes, NOX2 was expressed almost 2fold in aged myocytes (Young: $1.01 \pm 0.14$ a.u., n=7; Aged: 1.90 \pm 0.35 a.u.; $n=6$ ). NOX4 expression was augmented more than 3 fold in aged myocytes (Young: $1.58 \pm 0.26$ a.u., $\mathrm{n}=7$; Aged: $5.51 \pm 1.27$ a.u.; $\mathrm{n}=6$ ). Similarly, aging significantly increased expression of p47phox (Young: $1.25 \pm 0.16$ a.u., n=7; Aged: 2.48 \pm 0.55 a.u.; $n=6$ ). In contrast, expression of p22phox (Young: $0.71 \pm 0.14$ a.u., $n=7$; Aged: $0.66 \pm 0.06$ a.u.; $n=6$ ) and the small G-protein rac1 (Young: $0.77 \pm 0.11$ a.u., $n=7$; Aged: $0.84 \pm 0.08$ a.u.; $n=6$ ) remained unchanged with aging.

NADPH oxidase activity was quantified by means of lucigenin chemiluminescence in homogenates of isolated myocytes (Fig. 6B). Chemiluminescence was significantly augmented in aged myocytes (Young: $73630 \pm 12281 \mathrm{RLU}\left(\mathrm{mg}\right.$ protein) ${ }^{-1} \mathrm{~min}^{-1}, \mathrm{n}=5$; 
Aged: $119944 \pm 5607$ RLU (mg protein) ${ }^{-1} \min ^{-1}$; $n=5$ ). In both groups, pre-treatment with tiron $(n=5)$ or DPI $(n=5)$ significantly reduced the chemiluminescence signal by approx. 95\%. In contrast, pre-incubation with L-NAME $(n=5)$ had no significant effect on chemiluminescence.

\section{Discussion}

In this report, we show that aged murine ventricular myocytes are characterized by alterations in calcium transients and myofilament function that result in slowed contraction kinetics. These alterations are sensitive to the superoxide scavenger tiron. Furthermore, shortening and relengthening of aged myocytes are accelerated by the NADPH oxidase inhibitors DPI and apocynin. Our analyses indicate increased mRNA expression of NADPH oxidase subunits and augmented NADPH oxidase activity in aged myocytes. Collectively, these data suggest that augmented NADPH oxidasedependent superoxide formation contributes to the age-dependent impairment of contraction kinetics by modulation of calcium handling and myofilament function.

\section{Effect of the duration of membrane depolarisation on age-dependent changes of} contraction

In previous studies on age-dependent changes, supra-threshold field stimulation was used to elicit contractions of ventricular myocytes (Capasso et al., 1992; Li et al., 2005; Yang et al., 2006). This method does not allow for the control of action potential duration of myocytes. This is important because aged myocytes show action potential prolongation with concomitant delay in calcium channel inactivation supporting prolonged calcium influx (Capasso et al., 1983; Walker et al., 1993). Therefore, compared to young myocytes field stimulation is expected to impose a larger calcium 
load on aged myocytes that without further signalling per se could challenge calcium handling machinery.

In contrast, we used rectangular voltage clamp pulses a method that facilitates application of identical membrane depolarisations to young and aged myocytes. When myocytes were paced with $40 \mathrm{~ms}$ pulses, fractional shortening was reduced in aged myocytes confirming results of a previous study by Grandy \& Howlett (2006). However, in our study age-related differences in fractional shortening were no longer evident when myocytes were paced with 160 ms voltage clamp pulses. It was suggested that the age-dependent delay of calcium channel inactivation and action potential prolongation is an adaptation of aged myocytes to preserve normal fractional shortening by increasing calcium influx (Janczewski et al., 2002). Accordingly, application of short depolarisations to young and aged myocytes attenuates this adaptation and thus compromises fractional shortening of aged myocytes whereas long voltage clamp pulses support adaptation and normal fractional shortening.

Although we applied long voltage clamp pulses that exceed normal action potential duration, we could confirm the age-related deceleration of shortening/ relengthening of aged myocytes as previously reported using field stimulation (Capasso et al., 1992; Li et al., 2005; Yang et al., 2006). Using a different mode of electrical pacing than previous studies, we show that prolonged membrane depolarization of aged myocytes is critical for the age-dependent alterations in contraction kinetics. Thus, in our study we applied long voltage clamp pulses to stimulate calcium transients and contractions. 
Deceleration of shortening/ relengthening of aged myocytes could result from analogous alterations in the calcium transients of aged myocytes. In our study, this was not the case. Time to peak calcium concentration was similar between young and aged myocytes. However, the amplitude of the calcium transients and time to $70 \%$ calcium decay were increased in the aged group. This suggests additional age-dependent changes in the function of myofilaments. For the first time, we could demonstrate a reduced calcium sensitivity of myofilaments of aged myocytes by analysis of myofilament ATPase activity. Due to this finding the data on contractions can be conclusively brought together with the calcium transient analyses. Thus, aging changes the contractile phenotype of myocytes in a complex way affecting calcium homeostasis as well as myofilament function.

\section{Cardiac expression of calcium handling proteins during aging in C57BL/6 mice}

Calcium handling deficiency with subsequent contractile dysfunction of aged myocytes could be due to an altered expression of calcium handling proteins as it was shown for SERCA2 in human cardiac aging (Lakatta, 1993). Similarly, reduced cardiac expression of SERCA2 was demonstrated for aged rats and FVB mice, respectively (Buttrick et al., 1991; Lompre et al., 1991; Li et al., 2007). However, previously we could not find any age-dependent change in cardiac SERCA2 expression in C57BL/6 mice (Isenberg et al., 2003). Additionally, we show that aging had no effect on the expression of DHP receptor $\alpha$ subunit, RyR2, phospholamban, calsequestrin and NCX1 confirming previous analyses by other groups (Li et al., 2007; Xu and Narayanan, 1998). In conclusion, it seems very unlikely that in the mouse strain C57BL/6 altered calcium handling protein expression accounts for the contractile dysfunction of aged ventricular 
myocytes. Therefore, in this model post-translational mechanisms have to be responsible for the observed age-dependent differences in myocytes function.

NADPH oxidase-dependent superoxide formation decelerates contraction in aged myocytes

It is known that the activity of calcium handling proteins can be modulated by oxidative modification (Stamler and Hausladen, 1998) and that oxidative stress accumulates with aging (Adler et al., 2003; Sawada and Carlson, 1987). However, until now only a few studies have tried to analyse the impact of age-related changes in radical formation on calcium handling and contraction in ventricular myocytes. One study showed coincidence of age-related increase in oxidative stress and impairment of contractions without proving a causal relationship between both phenomena (Li et al., 2005). Recently, the same group showed prevention of age-related contractile dysfunction by lifelong constitutive cardiac-specific overexpression of antioxidative enzymes (Ren et al., 2007; Yang et al., 2006).

With our study, we further support the idea that reactive oxygen species causally contribute to age-related slowing of contractions. For the first time, we demonstrate that on the cellular level also short-term antioxidative treatment normalizes age-dependent contractile dysfunction of cardiac myocytes by affecting different processes of excitation-contraction coupling.

First, the calcium homeostasis is corrected, since pre-incubation of aged myocytes with the superoxide scavenger tiron normalized calcium transient amplitude and accelerated calcium decay. We speculate about the calcium release channel of the sarcoplasmic reticulum to be involved in these effects since it is known that oxidative modification of 
hyperactive SH-groups modulates ryanodine receptor channel activity. As a consequence, augmented RyR2 activation due to increased sensitivity to cytosolic calcium or reduced interaction with the inhibitory regulator calmodulin has been reported (Balshaw et al., 2001; Marengo et al., 1998) that would favour increased calcium transient amplitude. On the other hand, due to oxidative modification the RyR2 channel becomes leaky (Mochizuki et al., 2007), contributing to a slowed calcium decay by ongoing calcium efflux from the sarcoplasmic reticulum. However, the role of RyR2 as a target for age-dependent oxidative modulation should be proved in future studies i.e. by analyzing putative age-dependent redox-sensitive changes in calcium spark frequency and duration. Beside RyR2, SERCA2, the L-type $\mathrm{Ca}^{2+}$ channel and the NCX have been shown to be modulated by oxidative modifications (Kaneko et al., 1989; Kukreja et al., 1991; Gill et al., 1995; Goldhaber, 1996). Therefore, also these calcium handling proteins are putative targets of age-related increased superoxide formation. Additionally, we found that the reduced calcium sensitivity of myofilament ATPase of aged myocytes was corrected by pre-incubation with the superoxide scavenger tiron. This suggests age-dependent functional modulation of the acto-myosin complex by superoxide. This view is supported by a recent study showing reduced calcium sensitivity of myofibrillar ATPase after ischemia-reperfusion of the rat heart that was prevented by application of antioxidants (Maddika et al., 2009).

As a consequence of these tiron-mediated effects on calcium transients and myofilament ATPase activity contraction kinetics of aged myocytes is normalized.

We wondered about the source of superoxide mediating the age-dependent functional alterations. Therefore, we analyzed contraction of aged myocytes in response to the structurally unrelated NADPH oxidase inhibitors apocynin and DPI. Similar to tiron, 
both inhibitors accelerated shortening/ relengthening suggesting cardiac myocytes NADPH oxidases to be the source of the involved superoxide anions.

Recently, it was suggested that in vascular cells apocynin predominantly acts as a scavenger of reactive oxygen species but not as an inhibitor of NADPH oxidases (Heumüller et al., 2008). For the following reasons this might not apply to our study. Using tiron, we clearly demonstrated that superoxide is a mediator of the age-dependent slowing of contractions. However, according to Heumüller et al. (2008) substantial scavenging of superoxide depends on high concentrations of apocynin (> $300 \mu \mathrm{mol} / \mathrm{L})$ that are far beyond the concentration used in our study. Alternatively, since apocynin scavenges hydrogen peroxide also at lower concentrations (Heumüller et al., 2008) one could speculate that the superoxide was converted into hydrogen peroxide that in turn mediated the deceleration of contraction. However, this conversion critically depends on superoxide dismutase activity that is known to decline in aging hearts of rats and mice (van der Loo et al., 2005; Vaanholt et al., 2008). Therefore, in the aged heart an increased formation of hydrogen peroxide from superoxide seems to be unlikely.

Considering these facts, we think our data provide evidence that superoxide derived from cardiac myocytes NADPH oxidase substantially contributes to the development of age-dependent contractile dysfunction. Nevertheless, this finding does not exclude other potential cellular sources of ROS. For example, the mitochondrial electron transport chain could be involved as well since it was shown that constitutive mitochondriatargeted overexpression of catalase also prevents age-dependent alterations in contractile performance (Dai et al., 2009).

Concerning NADPH oxidase, we could demonstrate increased activity in aged myocytes using the lucigenin chemiluminescence assay. For both young and aged 
myocytes, the signal was reduced by more than $95 \%$ using DPI. We have to admit that DPI is a flavoprotein inhibitor. Consequently, it inhibits flavin-containing NADPH oxidases but also other flavoproteins. With regard to our assay conditions, DPI might also have inhibited the flavin-containing NO synthases that in a specific setting (substrate or cofactor deficiency) can generate superoxide upon stimulation with NADPH. Therefore, the contribution of NO synthases to the DPI-sensitive chemiluminescence signal was tested using L-NAME. Since L-NAME had no effect, we conclude that the recorded signal derived from superoxide generated by NADPH oxidases that are functionally upregulated in aged murine myocytes.

Increased NADPH oxidase activity may result from an increased expression. We tried to quantify subunit expression. Unfortunately, in our hands commercially available antibodies to NADPH oxidase subunits failed to give distinct signals in Western blot experiments using murine whole heart homogenates. Therefore, we analyzed mRNA expression in isolated ventricular myocytes although we know that these results might not necessarily translate into identical changes on protein level. Nevertheless, we found increased expression of p47phox as well as NOX2 and NOX4, the two core subunits of NADPH oxidase expressed in cardiac myocytes (Byrne et al., 2003). Our findings confirm and extend previous reports on NADPH oxidase expression and support increased NADPH oxidase activity in aged rodent hearts (Adler et al., 2003; Li et al., 2005; Yang et al., 2006).

In our study, even short-term antioxidative intervention attenuated age-dependent alterations in cardiac myocytes function. But the efficacy of antioxidants like Vitamin E to correct for age-dependent cardiac alterations in humans is questionable since it also has failed to show consistent beneficial effects in clinical trials on cardiovascular 
diseases (for putative reasons of failure see Robinson et al, 2006). However, oxidative stress results from an imbalance between formation and decomposition of reactive oxygen species. Therefore, oxidative stress due to an increased formation of reactive oxygen species could also be attenuated by a compensatory upregulation of antioxidative enzyme activity. It was demonstrated that regular physical activity increases antioxidative capacity in the rat heart or human skeletal muscle (Powers et al., 1993; Venditti and Di Meo, 1996; Husain, 2003; Ennezat et al., 2001; Linke et al., 2005). These findings could provide an explanation for the observation that lifelong physical activity effectively prevents age-related cardiac contractile dysfunction (ArbabZadeh et al., 2004).

In summary, we show augmented NADPH oxidase-dependent superoxide formation in aged myocytes and causally link these changes to the observed decelerated contraction kinetics of cardiac myocytes from aged mice. Further studies are needed to identify the target proteins of oxidative modification that mediate altered calcium homeostasis and myofilament function during cardiac aging.

\section{Acknowledgements}

We thank Lars Dressler and Dr. Stefanie Ruhs for technical assistance.

This study was supported by the Wilhelm Roux grant of the Bundesministerium für Bildung und Forschung, BMBF granted to U.R. (NBL3 program, FKZ 12/24).

\section{Disclosure Statement}

All authors disclose any actual or potential conflict of interest. 


\section{References}

Adler, A., Messina, E., Sherman, B., Wang, Z., Huang, H., Linke, A., Hintze, T.H., 2003. NAD(P)H oxidase-generated superoxide anion accounts for reduced control of myocardial $\mathrm{O} 2$ consumption by NO in old Fischer 344 rats. Am. J. Physiol. Heart Circ. Physiol. 285, H1015-H1022.

Arbab-Zadeh, A., Dijk, E., Prasad, A., Fu, Q., Torres, P., Zhang, R., Thomas, J.D., Palmer, D., Levine, B.D., 2004. Effect of aging and physical activity on left ventricular compliance. Circulation. 110, 1799-1805.

Balshaw, D.M., Xu, L., Yamaguchi, N., Pasek, D.A., Meissner, G., 2001. Calmodulin binding and inhibition of cardiac muscle calcium release channel (ryanodine receptor). J. Biol. Chem. 276, 20144-20153.

Buttrick, P., Malhotra, A., Factor, S., Greenen, D., Leinwand, L., Scheuer, J., 1991. Effect of aging and hypertension on myosin biochemistry and gene expression in the rat heart. Circ. Res. 68: 645-652.

Byrne, J.A., Grieve, D.J., Bendall, J.K., Li, J.M., Gove, C., Lambeth, J.D., Cave, A.C., Shah, A.M., 2003. Contrasting roles of NADPH oxidase isoforms in pressureoverload versus angiotensin II-induced cardiac hypertrophy. Circ. Res. 93, 802805.

Cailleret, M., Amadou, A., Andrieu-Abadie, N., Nawrocki, A., Adamy, C., Ait-Mamar, B., Rocaries, F., Best-Belpomme, M., Levade, T., Pavoine, C., Pecker, F., 2004. $\mathrm{N}$-Acetylcysteine prevents the deleterious effect of tumor necrosis factor- $\alpha$ on calcium transients and contraction in adult rat cardiomyocytes. Circulation. 109, 406-411. 
Capasso, J.M., Malhotra, A., Remily, R.M., Scheuer, J., Sonnenblick, E.H., 1983. Effects of age on mechanical and electrical performance of rat myocardium. Am. J. Physiol. 245, H72-H81.

Capasso, J.M., Fitzpatrick, D., Anversa, P., 1992. Cellular mechanisms of ventricular failure: myocyte kinetics and geometry with age. Am. J. Physiol. 262, H1770H781.

Carter, G.S., Karl, D.W., 1982. Inorganic phosphate assay with malachite green: An improvement and evaluation. J. Biochem. Biophys. Methods. 7, 7-13.

Corretti, M.C., Koretsune, Y., Kusuoka, H., Chacko, V.P., Zweier, J.L., Marban, E., 1991. Glycolytic inhibition and calcium overload as consequences of exogenously generated free radicals in rabbit hearts. J. Clin. Invest. 88, 1014-1025.

Dai, D.F., Santana, L.F., Vermulst, M., Tomazela, D.M., Emond, M.J., MacCoss, M.J., Gollahon, K., Martin, G.M., Loeb, L.A., Ladiges, W.C., Rabinovitch, P.S., 2009. Overexpression of catalase targeted to mitochondria attenuates murine cardiac aging. Circulation. 119, 2789-2797.

Dworschak, M., Breukelmann, D., Hannon, J.D., 2004. Isoflurane applied during ischemia enhances intracellular calcium accumulation in ventricular myocytes in part by reactive oxygen species. Acta Anaesthesiol. Scand. 48, 716-721.

Ennezat, P.V., Malendowicz, S.L., Testa, M., Colombo, P.C., Cohen-Solal, A., Evans, T., LeJemtel, T.H., 2001. Physical training in patients with chronic heart failure enhances the expression of genes encoding antioxidative enzymes. J. Am. Coll. Cardiol. 38, 194-198. 
Froehlich, J.P., Lakatta, E.G., Beard, E., Spurgeon, H.A., Weisfeldt, M.L., Gerstenblith, G., 1978. Studies of sarcoplasmic reticulum function and contraction duration in young adult and aged rat myocardium. J. Mol. Cell. Cardiol. 10, 427-438.

Gill, J.S., McKenna, W.J., Camm, A., 1995. Free radicals irreversibly decrease Ca2+ currents in isolated guinea-pig ventricular myocytes. Eur. J. Pharmacol. 292, 337340.

Goldhaber, J.I., 1996. Free radicals enhance $\mathrm{Na}+/ \mathrm{Ca} 2+$ exchange in ventricular myocytes. Am. J. Physiol. 271, H823-H833.

Grandy, S.A., Howlett, S.E., 2006. Cardiac excitation-contraction coupling is altered in myocytes from aged male mice but not in cells from aged female mice. Am. J. Physiol. Heart Circ. Physiol. 291, H2362-H2370.

Heumüller, S., Wind, S., Barbosa-Sicard, E., Schmidt, H.H., Busse, R., Schröder, K., Brandes, R.P., 2008. Apocynin is not an inhibitor of vascular NADPH oxidases but an antioxidant. Hypertension. 51, 211-217.

Husain, K., 2003. Interaction of exercise training and chronic NOS inhibition on blood pressure, heart rate, NO and antioxidants in plasma of rats. Pathophysiology. 10, 47-56.

Isenberg, G., Borschke, B., Rueckschloss, U., 2003. $\mathrm{Ca}^{2+}$ transients of cardiomyocytes from senescent mice peak late and decay slowly. Cell Calcium. 34, 271-280.

Janczewski, A.M., Spurgeon, H.A., Lakatta, E.G., 2002. Action potential prolongation in cardiac myocytes of old rats is an adaptation to sustain youthful intracellular Ca2+ regulation. J. Mol. Cell. Cardiol. 34, 641-648.

Kamkin, A., Kiseleva, I., Isenberg, G., 2003. Ion selectivity of stretch-activated cation currents in mouse ventricular myocytes. Pflugers Arch. 446, 220-231. 
Kaneko, M., Elimban, V., Dhalla, N.S., 1989. Mechanism for depression of heart sarcolemmal Ca2+ pump by oxygen free radicals. Am. J. Physiol. 257, H804H811.

Kukreja, R.C., Kearns, A.A., Zweier, J.L., Kuppusamy, P., Hess, M.L., 1991. Singlet oxygen interaction with $\mathrm{Ca}(2+)$-ATPase of cardiac sarcoplasmic reticulum. Circ. Res. 69, 1003-1014.

Lakatta, E.G., 1993. Cardiovascular regulatory mechanisms in advanced age. Physiol. Rev. 73, 413-467.

Li, Q., Wu, S., Li, S.Y., Lopez, F.L., Du, M., Kajstura, J., Anversa, P., Ren, J., 2007. Cardiac-specific overexpression of insulin-like growth factor 1 attenuates agingassociated cardiac diastolic contractile dysfunction and protein damage. Am. J. Physiol. Heart Circ. Physiol. 292, H1398-H1403.

Li, S.Y., Du, M., Dolence, E.K., Fang, C.X., Mayer, G.E., Ceylan-Isik, A.F., LaCour, K.H., Yang, X., Wilbert, C.J., Sreejayan, N., Ren, J., 2005. Aging induces cardiac diastolic dysfunction, oxidative stress, accumulation of advanced glycation endproducts and protein modification. Aging Cell. 4, 57-64.

Limouze, J., Straight, A.F., Mitchison, T., Sellers, J.R., 2004. Specificity of blebbistatin, an inhibitor of myosin II. J. Muscle Res. Cell. Motil. 2, 337-341.

Linke, A., Adams, V., Schulze, P.C., Erbs, S., Gielen, S., Fiehn, E., Möbius-Winkler, S., Schubert, A., Schuler, G., Hambrecht, R., 2005. Antioxidative effects of exercise training in patients with chronic heart failure: increase in radical scavenger enzyme activity in skeletal muscle. Circulation. 111, 1763-1770. 
Lompre, A.M., Lambert, F., Lakatta, E.G., Schwartz, K., 1991. Expression of sarcoplasmic reticulum $\mathrm{Ca}(2+)$-ATPase and calsequestrin genes in rat heart during ontogenic development and aging. Circ. Res. 69, 1380-1388.

Maddika, S., Elimban, V., Chapman, D., Dhalla, N.S., 2009. Role of oxidative stress in ischemia-reperfusion-induced alterations in myofibrillar ATPase activities and gene expression in the heart. Can. J. Physiol. Pharmacol. 87, 120-129.

Marengo, J.J., Hidalgo, C., Bull, R., 1998. Sulfhydryl oxidation modifies the calcium dependence of ryanodine-sensitive calcium channels of excitable cells. Biophys. J. $74,1263-1277$.

Mochizuki, M., Yano, M., Oda, T., Tateishi, H., Kobayashi, S., Yamamoto, T., Ikeda, Y., Ohkusa, T., Ikemoto, N., Matsuzaki, M., 2007. Scavenging free radicals by low-dose carvedilol prevents redox-dependent $\mathrm{Ca} 2+$ leak via stabilization of ryanodine receptor in heart failure. J. Am. Coll. Cardiol. 49, 1722-1732.

Pi, Y., Zhang, D., Kemnitz, K.R., Wang, H., Walker, J.W., 2003. Protein kinase C and A sites on troponin I regulate myofilament $\mathrm{Ca} 2+$ sensitivity and ATPase activity in the mouse myocardium. J. Physiol. 552, 845-857.

Powers, S.K., Criswell, D., Lawler, J., Martin, D., Lieu, F.K., Ji, L.L., Herb, R.A., 1993. Rigorous exercise training increases superoxide dismutase activity in ventricular myocardium. Am. J. Physiol. Heart Circ. Physiol. 265, H2094-H2098.

Ren, J., Li, Q., Wu, S., Li, S.Y., Babcock, S.A., 2007. Cardiac overexpression of antioxidant catalase attenuates aging-induced cardiomyocyte relaxation dysfunction. Mech. Ageing Dev. 128, 276-285.

Robinson, I., de Serna, D.G., Gutierrez, A., Schade, D.S., 2006. Vitamin E in humans: an explanation of clinical trial failure. Endocr. Pract. 12, 576-582. 
Sawada, M., Carlson, J.C., 1987. Changes in superoxide radical and lipid peroxide formation in the brain, heart and liver during the lifetime of the rat. Mech. Ageing Dev. 41, 125-137.

Stamler, J.S., Hausladen, A., 1998. Oxidative modifications in nitrosative stress. Nat. Struct. Biol. 5, 247-249.

Vaanholt, L.M., Speakman, J.R., Garland, T. Jr., Lobley, G.E., Visser, G.H., 2008. Protein synthesis and antioxidant capacity in aging mice: effects of long-term voluntary exercise. Physiol. Biochem. Zool. 81, 148-157.

van der Loo, B., Bachschmid, M., Labugger, R., Schildknecht, S., Kilo, J., Hahn, R., Palacios-Callender, M., Luscher, T.F., 2005. Expression and activity patterns of nitric oxide synthases and antioxidant enzymes reveal a substantial heterogeneity between cardiac and vascular aging in the rat. Biogerontology. 6, 325-334.

Venditti, P., Di Meo, S., 1996. Antioxidants, tissue damage, and endurance in trained and untrained young male rats. Arch. Biochem. Biophys. 331, 63-68.

Walker, K.E., Lakatta, E.G., Houser, S.R., 1993. Age associated changes in membrane currents in rat ventricular myocytes. Cardiovasc. Res. 27, 1968-1977.

Xu, A., Narayanan, N., 1998. Effects of aging on sarcoplasmic reticulum Ca2+-cycling proteins and their phosphorylation in rat myocardium. Am. J. Physiol. 275, H2087-H2094.

Yang, X., Doser, T.A., Fang, C.X., Nunn, J.M., Janardhanan, R., Zhu, M., Sreejayan, N., Quinn, M.T., Ren, J., 2006. Metallothionein prolongs survival and antagonizes senescence-associated cardiomyocyte diastolic dysfunction: role of oxidative stress. FASEB J. 20, E260-E270. 
Fig. 1. Contractions of young and aged murine ventricular myocytes. Contractions from a young myocyte and an aged myocyte are illustrated on the left hand side. The complete recording includes pacing sequences from $0.5 \mathrm{~Hz}$ up to $4 \mathrm{~Hz}$; at higher temporal resolutions individual contractions at 0.5 and $2 \mathrm{~Hz}$ are shown.

Statistical analyses of contractions are provided on the right hand side. Young (open circles, $\mathrm{n}=16$ ) and aged (circles, $\mathrm{n}=18$ ) myocytes show similar fractional shortening, but time to peak shortening (TPS) as well as time to $70 \%$ relengthening $\left(\mathrm{TR}_{70}\right)$ are significantly prolonged in aged myocytes. $* \mathrm{P}<0.05$ vs. Young.

Fig. 2. Modulation of time to peak shortening (TPS) and time to 70\% relengthening $\left(\mathbf{T R}_{\mathbf{7 0}}\right)$ in aged myocytes by tiron, apocynin and DPI. Statistical analyses of aged myocytes (circles, $n=21$ ) and aged myocytes pre-treated with pharmacological agents (squares). Scavenging superoxide with tiron (A, $1 \mathrm{mmol} / \mathrm{L}$, $\mathrm{n}=12)$ and inhibition of NADPH oxidase using apocynin (B, $50 \mu \mathrm{mol} / \mathrm{L}, \mathrm{n}=9)$ or DPI $(\mathrm{C}, 10 \mu \mathrm{mol} / \mathrm{L}, \mathrm{n}=18)$ accelerate shortening and relengthening in aged murine myocytes. *P<0.05 Pre-treatment vs. Aged.

Fig. 3. Calcium transients of young and aged murine ventricular myocytes. In the upper part, representative traces of Indo-1 fluorescence are illustrated. Statistical analyses of calcium transients from young $(n=24)$ and aged $(n=32)$ myocytes, as well as myocytes pre-incubated with tiron ( $1 \mathrm{mmol} / \mathrm{L}$; Young: $\mathrm{n}=11$; Aged: $\mathrm{n}=33)$ are provided below. Time to peak calcium concentration (TPC) is unaffected by aging, but amplitude and time to $70 \%$ calcium decay $\left(\mathrm{TD}_{70}\right)$ are significantly increased in aged myocytes. These alterations are reversible upon pre-incubation with tiron. ${ }^{*} \mathrm{P}<0.05$ vs. Young. ${ }^{\S} \mathrm{P}<0.05$ vs. Aged. 


\section{Fig. 4. Myofilament ATPase activity of young and aged murine ventricular}

myocytes. (A) Statistical analysis of maximum myofilament ATPase activity shows no difference between young and aged myocytes.

(B) The calcium dependency of myofilament ATPase activity is illustrated. Myofilaments were prepared from isolated young myocytes (open circles), aged myocytes (closed circles) and aged myocytes pre-incubated with tiron $(1 \mathrm{mmol} / \mathrm{L}$; squares). For each group, blebbistatin-sensitive phosphate generation was determined from three independent experiments and data were normalized to the maximum myofilament ATPase activity (pCa 4.0). Results were fitted using the Hill equation. The calcium response curve of myofilaments prepared from aged myocytes is shifted rightwards as indicated by the significant difference in myofilament ATPase activity at pCa 6.0. This calcium desensitisation is corrected by tiron. $* \mathrm{P}<0.05$ Young vs. Aged. ${ }^{\S} \mathrm{P}<0.05$ Aged + Tiron vs. Aged.

Accordingly, in aged myocytes, calcium concentration for half-maximal activation is significantly increased, but normalized by pre-incubation with tiron (see inset; $* \mathrm{P}<0.05$ vs. Young. ${ }^{\S} \mathrm{P}<0.05$ vs. Aged).

Fig. 5. Expression of calcium handling proteins in young and aged murine hearts. For each protein, the immunological signal (upper panel) was normalized to the subsequent staining of the membrane for total protein with Ponceau S (lower panel). Structural and regulatory proteins involved in calcium handling are similarly expressed in young (open bars, $n=4$ ) and aged (filled bars, $n=5$ ) hearts.

Fig. 6. NADPH oxidase subunit expression and activity in young and aged murine ventricular myocytes. (A) Expression of several NADPH oxidase subunits was 
analyzed by real-time RT-PCR. Total RNA was prepared from isolated cardiac myocytes derived from young $(n=7)$ and aged $(n=6)$ murine hearts, respectively. NOX4, NOX2 and the cytosolic subunit p47phox are significantly upregulated in aged myocytes, whereas there is no difference in the expression of p22phox and the small Gprotein $\operatorname{rac} 1 . * \mathrm{P}<0.05$ vs. Young.

(B) NADPH oxidase activity was determined in lysates of young and aged myocytes ( $n=5$ for both groups) using the lucigenin chemiluminescence assay. In both groups, the chemiluminescence signal is sensitive to tiron $(10 \mathrm{mmol} / \mathrm{L})$ and DPI $(10 \mu \mathrm{mol} / \mathrm{L})$, but not L-NAME $(100 \mu \mathrm{mol} / \mathrm{L})$ indicating that it is caused by superoxide derived from NADPH oxidases but not from uncoupled NO synthase. NADPH oxidase activity is augmented in aged myocytes. ${ }^{*} \mathrm{P}<0.05$ vs. Young. ${ }^{\#} \mathrm{P}<0.05$ vs. Young. ${ }^{\S} \mathrm{P}<0.05$ vs. Aged. 

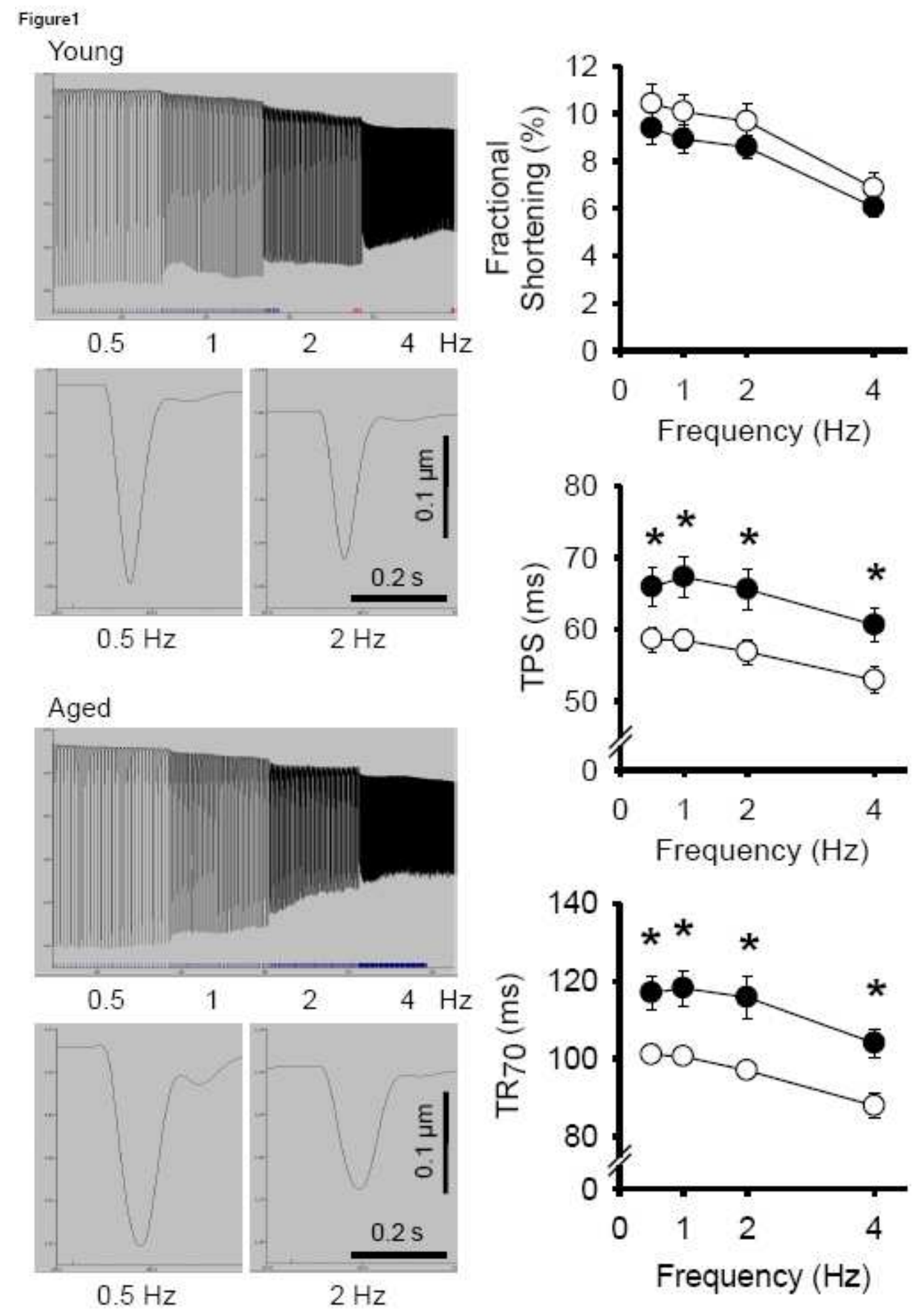


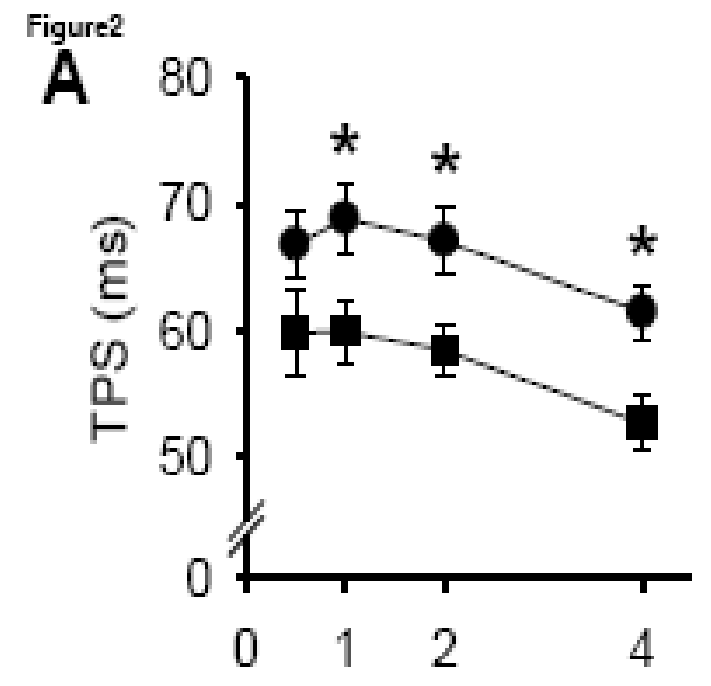

Frequency $(\mathrm{Hz})$

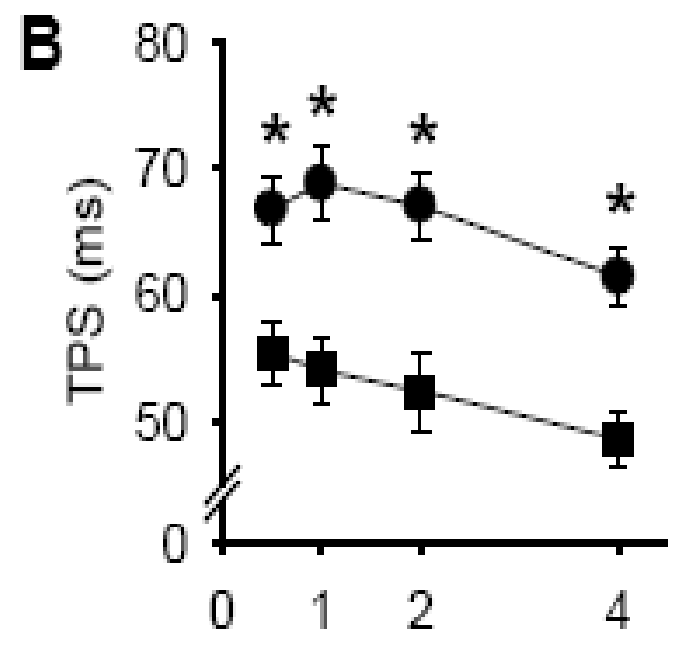

Frequency $(\mathrm{Hz})$

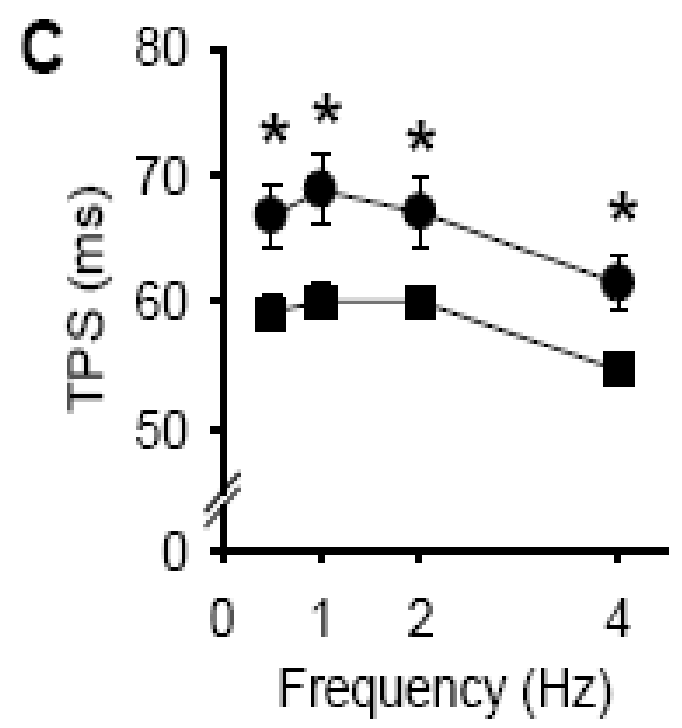

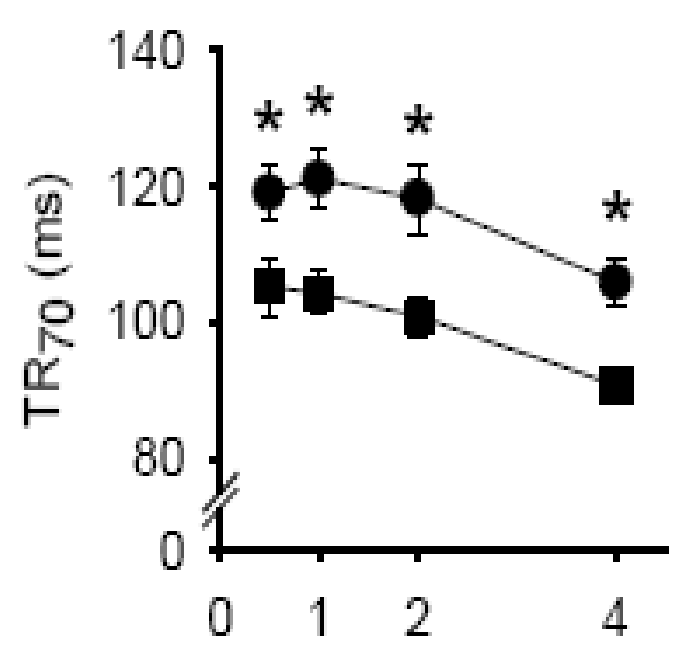

Frequency $(\mathrm{Hz})$
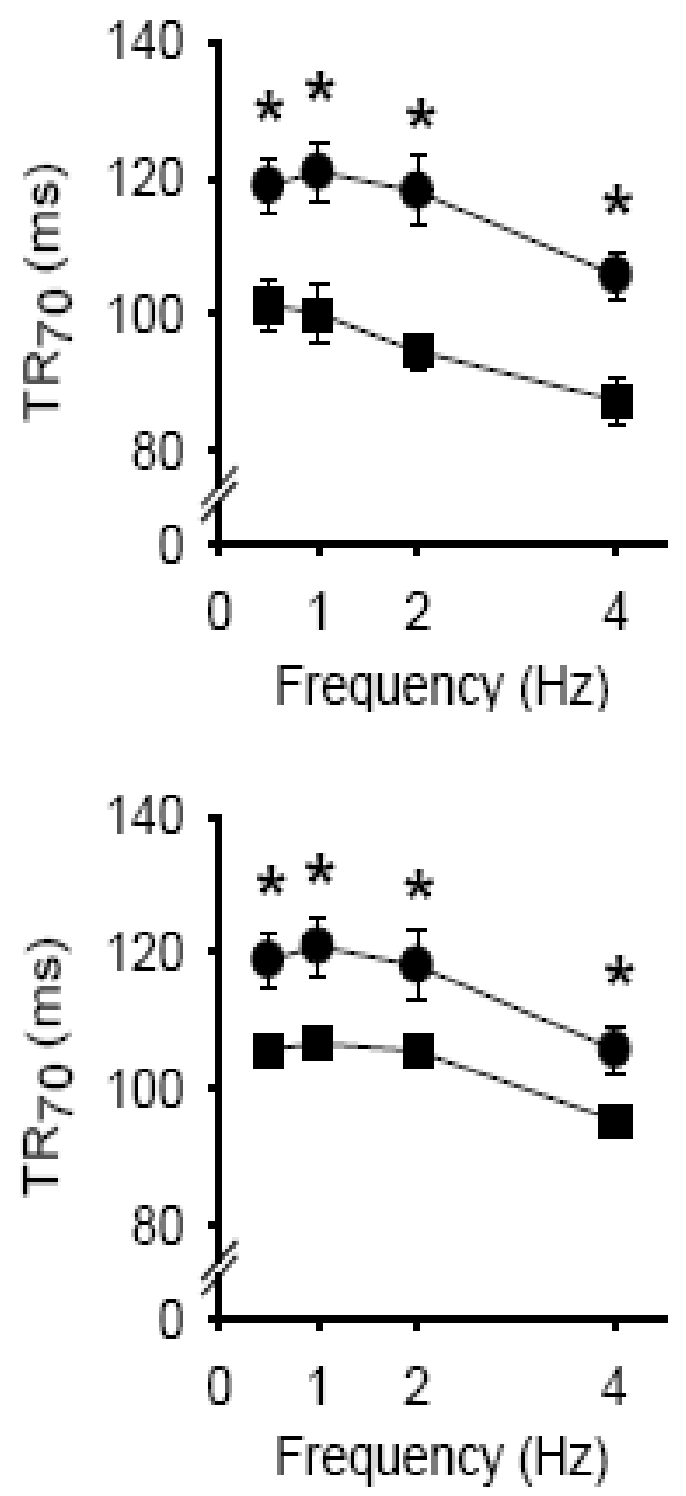
Figures

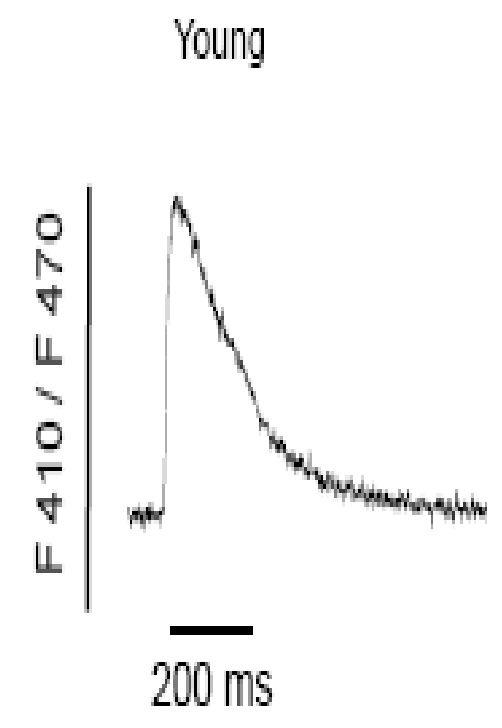

Aged

Aged + Tiron
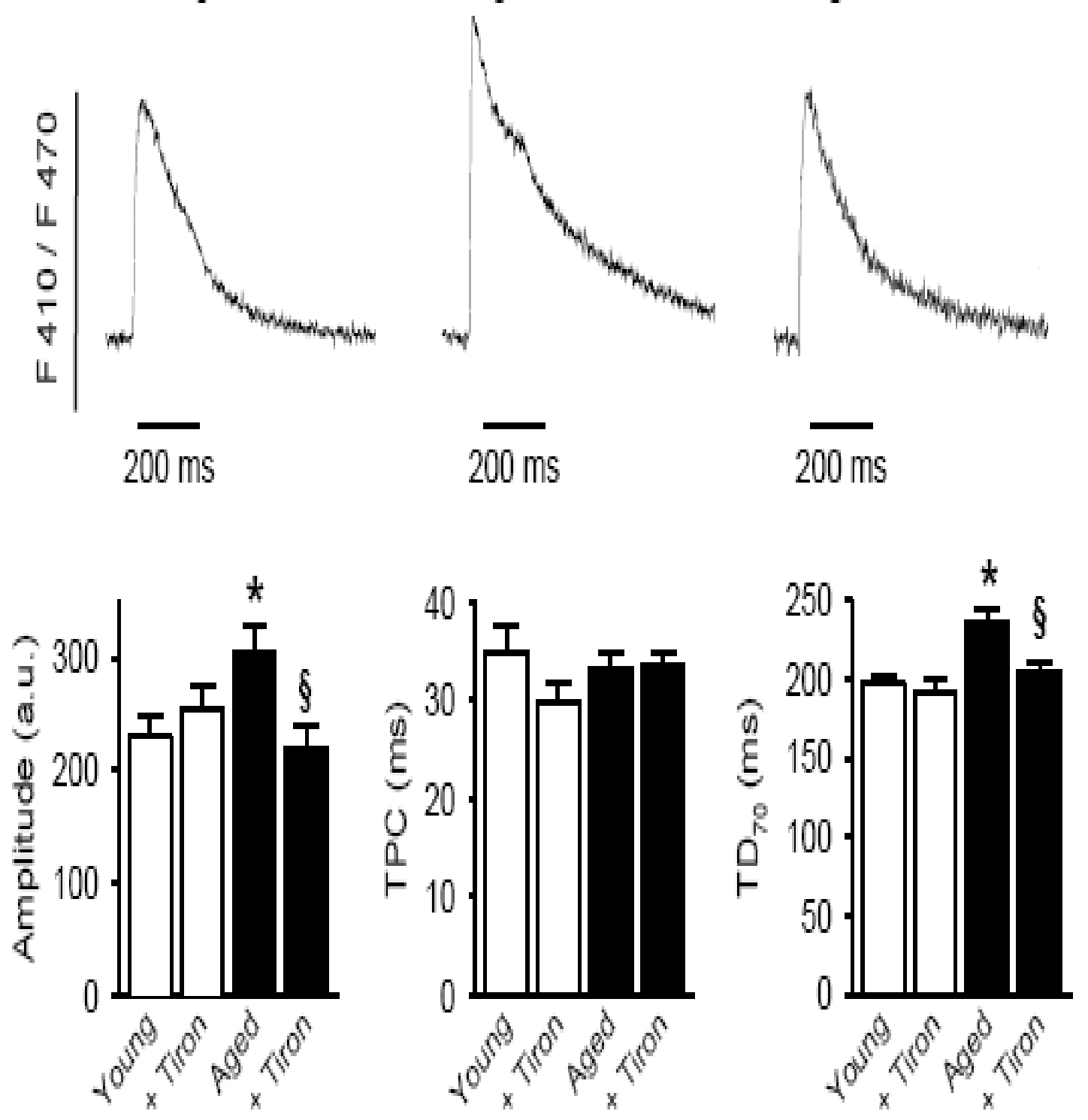
Figure4

A

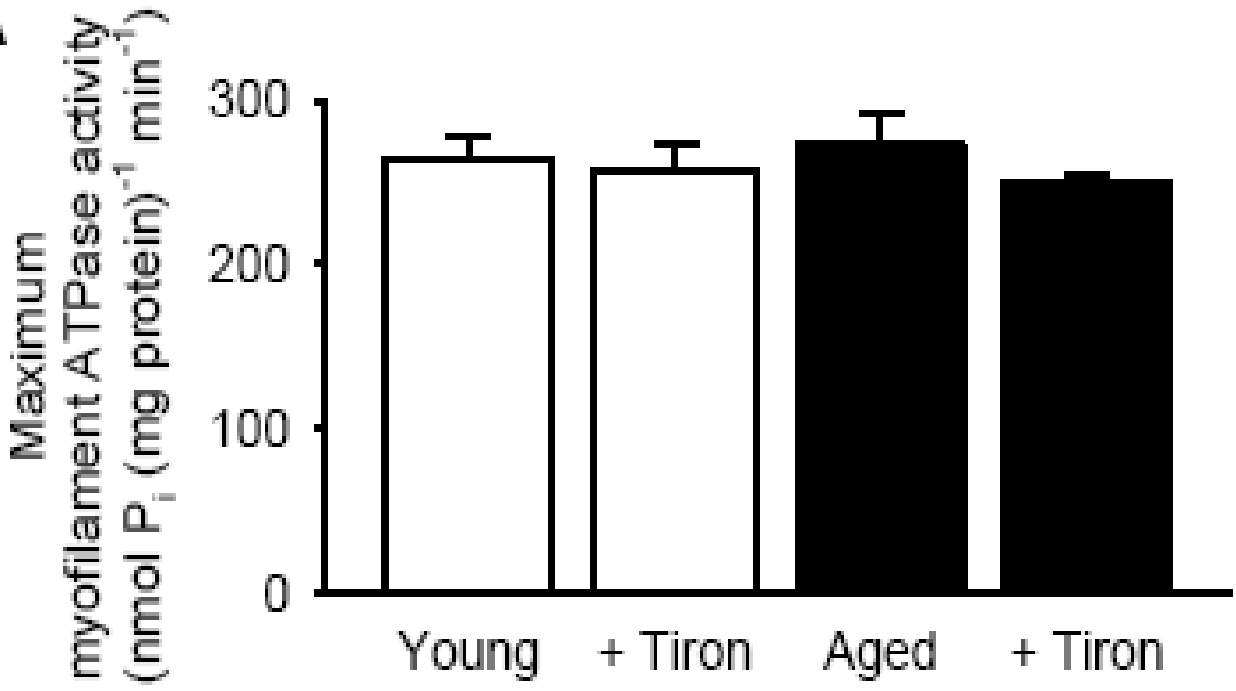

B

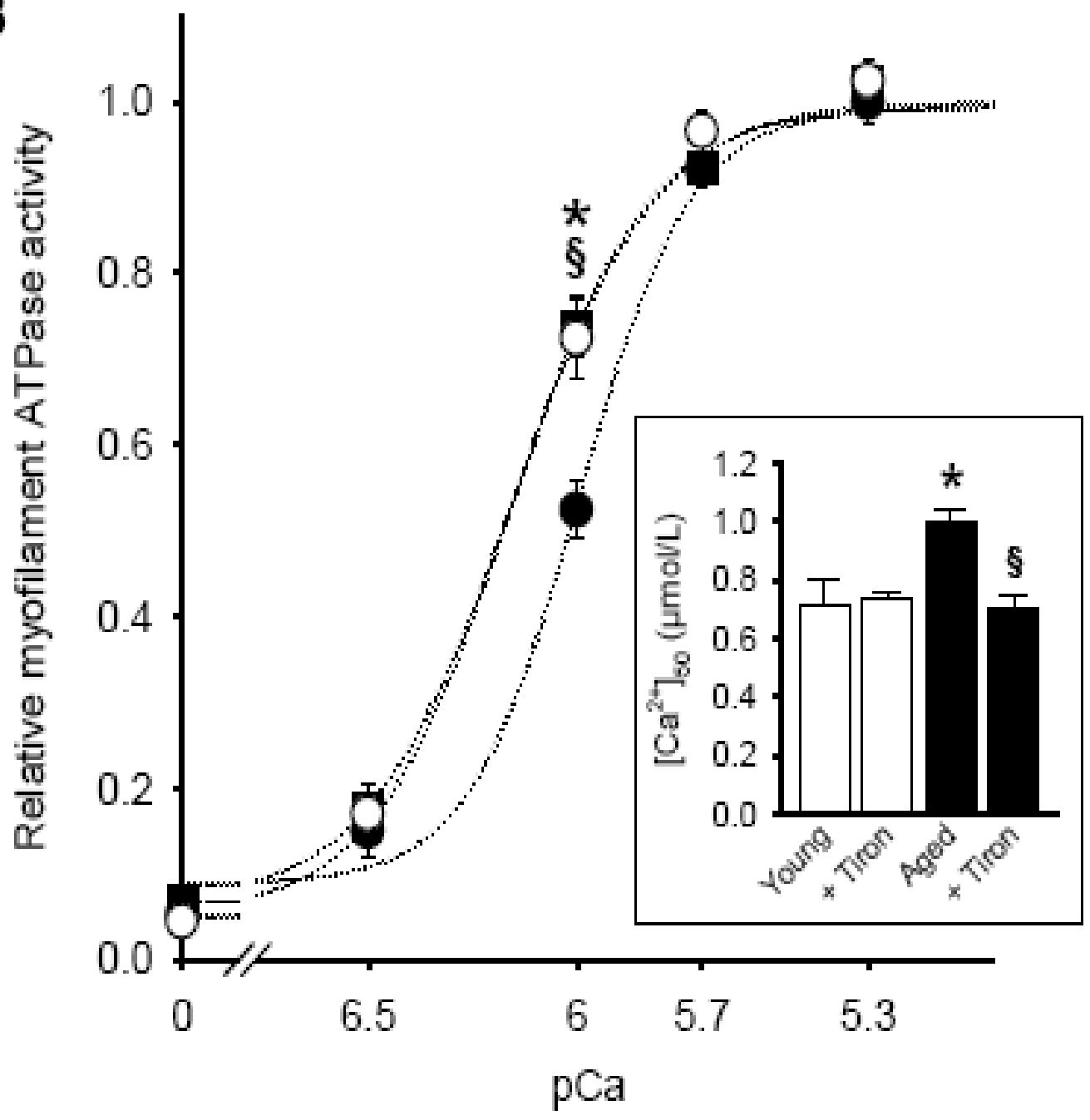


Figuret5
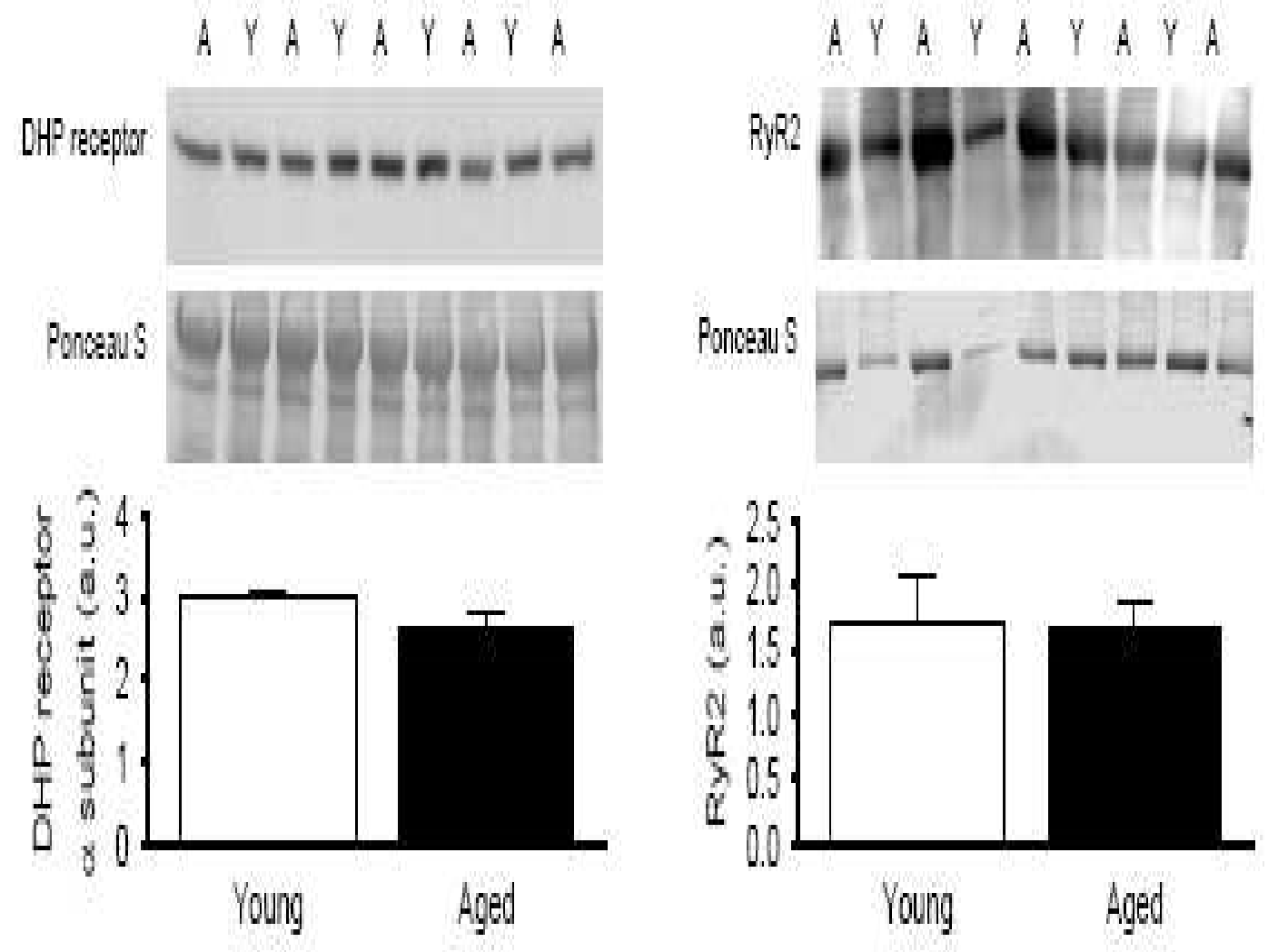

\section{A Y A Y A Y A Y A}

\section{A Y A Y A Y A Y A}

(ta) $P$. $B$

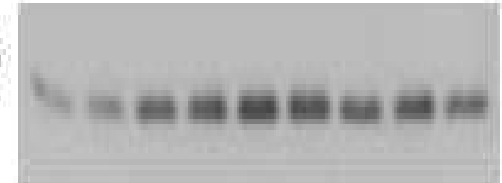

Gasenctiti
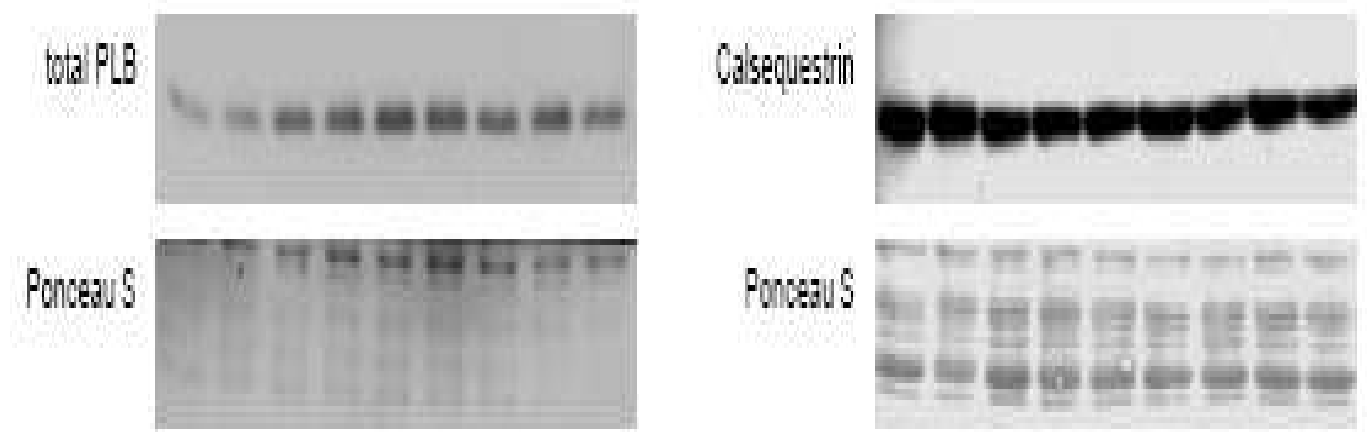

Poncaus
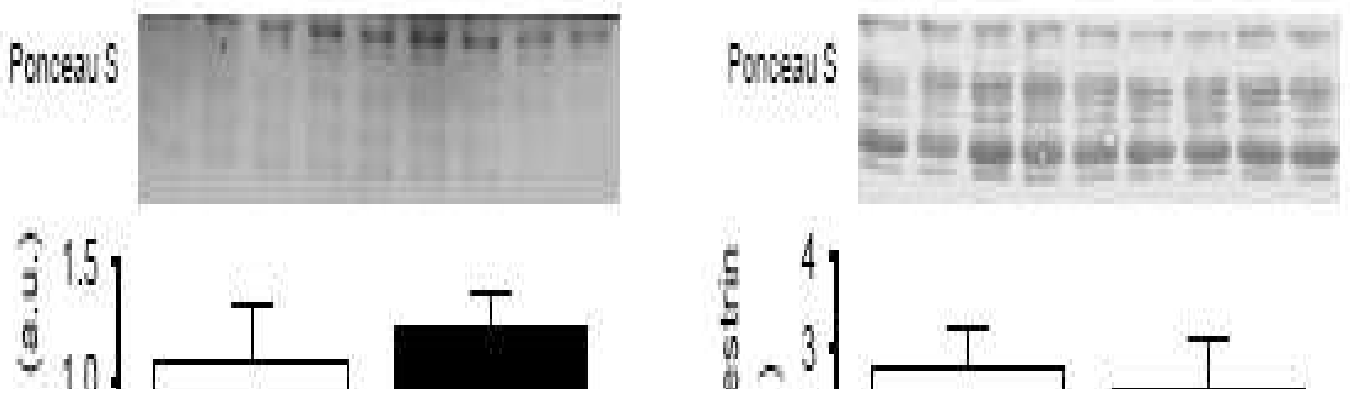

$\begin{array}{cc}5 \\ 5 & -3\end{array}$
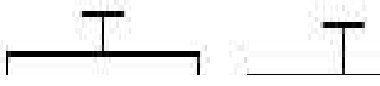
Figure6
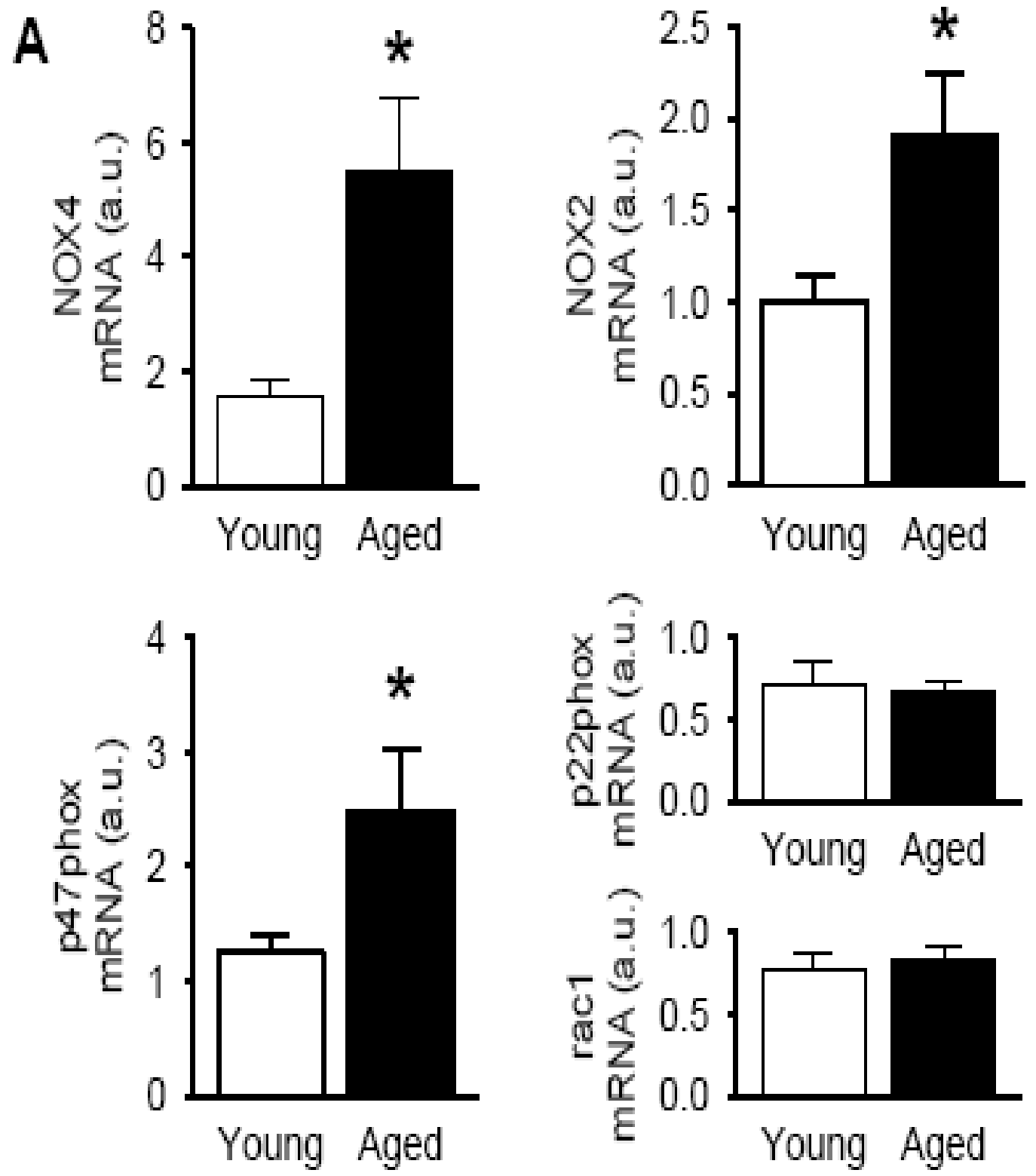

B
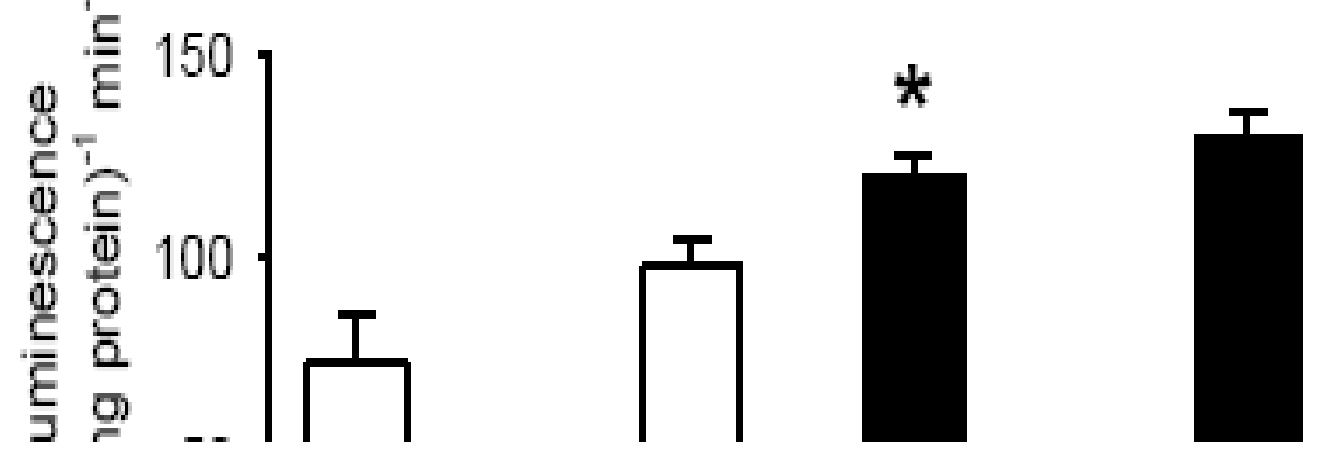